\title{
Intellekt The Mechanism For The Development Of Tasks Oriented To The Visual Potential.
}

\section{Murodova Zarina Rashidovna}

Assistant of the department of Information and communication technologies, Bukhara engineering technological institute, Uzbekistan.

E-mail: zarina_muradova_2005@mail.ru

Article History: Received:11 January 2021; Accepted: 27 February 2021; Published online: 5 April 2021

Abstract: The article one of the most important factors is the development of assignments for the formation and determination of intellektual capacity in the 9th grade students of secondary schools, their separation into weights, based on the laws of interdependence. It also requires research as a scientific and methodological issue to develop and implement the aktual capacity shaping single and subgroup approach and use methodology, intellektual capacity determination single and subgroup approach and use methodology in the course process.

Keywords: Innovation, information, virtual laboratory, educational and methodical material, learning tools, multimedia.

\section{Introduction}

Currently, it is used in determining the thinking of its students, their skills in working with numbers and their numbers. It is based on the study of the structure of such assignments and their impact onualual capacity, intellektual capacity can be assigned to the formation-oriented tasks. But on the one hand, it seems that it is not even right to distinguish them. Because intellektual capacity identification is also associated with the formation and invisible law of interaction

\section{Literature review}

We believe that the creation of the task development framework, which is focused on potential, depends on the following characteristics:

- $\quad$ An inseparable sequence of topics by chapter;

- $\quad$ Assignments and requirements to them;

- $\quad$ PDV and linkage of theoretical actions;

- $\quad$ Method of development of assignments;

- $\quad$ Assignment weight determination and priority of actions.

The satisfactory level of these characteristics intellekt serves to develop and determine the potential. In the same bunda it is possible to create a method of developing assignments according to one chapter or two chapters. But choosing a style in science and introducing it into science is a very difficult task. This can be seen especially in the science of Information Technology. Because in one class there are topics in at least 3 directions. It would also be targeted to use the method of developing assignments for a class in mathematics, but for a science that consists of sharply different chapters, it is necessary to develop on a chapter scale. General education schools 9th grade computer science and information technology has Chapter 3, algorithm basics, programming, Web page etc. Each chapter has its own theme. Chapters are sequential-appropriate, but chapterby-chapter assignments and table-solving tools and approaches, Pdvs are different. For the development of tasks and issues, first of all, it is necessary to rely on the principle of consistency of topics and consecutive teaching of concepts. chapter:

The basis of the algorithm we propose the following in an integral sequence of topics according to the

- $\quad$ The concept of the algorithm;

- $\quad$ Key hosts of the algorithm;

- $\quad$ Types of algorithm;

- Methods for describing the algorithm;

- $\quad$ Linear algorithms;

- $\quad$ Networked algorithms;

- $\quad$ Repetitive algorithms;

- $\quad$ Mixed (combined) algorithms.

\section{Discussion}

The assignments on these topics and the requirements for them are as follows:

1. The presence of certain undesirable parameters of the task.

2 . The presence of clear outgoing parameters of the task. 
3. To have at least one variant of finding a solution to the task.

4. The fact that to solve the task is based on the knowledge that the student has mastered before.

5. The presence of a method of solving the task with several interrelated knowledge.

It would seem that the development of assignments based on these requirements is often taken into account. But the authors also emphasize the need to simplify some of the features by introducing special cases in the solution of the task.

On the basis of requirements, it is possible to formulate issues and assignments, but to formulate and determine theualual capacity, we must look at two more feature, weight and genealogical assignments.

1. Mission weight - this is a feature that indicates the degree of difficulty of the task. On the basis of weight, it is possible to determine the capacity, resourcefulness, speed of the pupil.

2. Task genealogy - it is understood that the attribute of the task is connected (partially connected) to the previous task. Genealogy assignment shapes and strengthens the student's skills such as finding legitimacy, independent thinking, remembering, introducing previous experience.

The style of drawing up weight assignments can be based on a different approach on each topic or chapter. The number of formulas used in solving tasks for the formation and determination ofualual capacity in information technology is their weight.

An example of a weighting issue is $\mathrm{R}$ riadusli-make an algorithm for finding the length of the circle. Task, $\mathrm{L}=2 \cdot \pi \cdot \mathrm{R}$ find by formula. Therefore, it is considered one-weight.

An example of a two-weight issue is given the sides of a rectangular triangle, make an algorithm that finds its perimeter. Task, $c$ side of the first triangle to draw up an algorithm $c=\sqrt{a^{2}+b^{2}}$ and $P$ perimeter $P=$ $a+b+c$ it is determined by expressions. Therefore, it is considered two-weight.

An example of a three-weight issue is given variables a and $b$, make an algorithm for replacing their values without using additional variables. Such $a=a+b, b=a-b, a=a-b$ like 3 units of expression are used. Therefore, it is considered three-weight.

Based on the above examples, it can be noted that it is possible to understand that it is worthwhile to equate to the same weight if multiple formulas ( legality) are used to obtain a solution in the issue and tasks that are made to study the algorithm.

The system of genealogical-based assignments is much more complex than the development of these weighted assignments developed. It can be imagined based on the 1-th picture below.

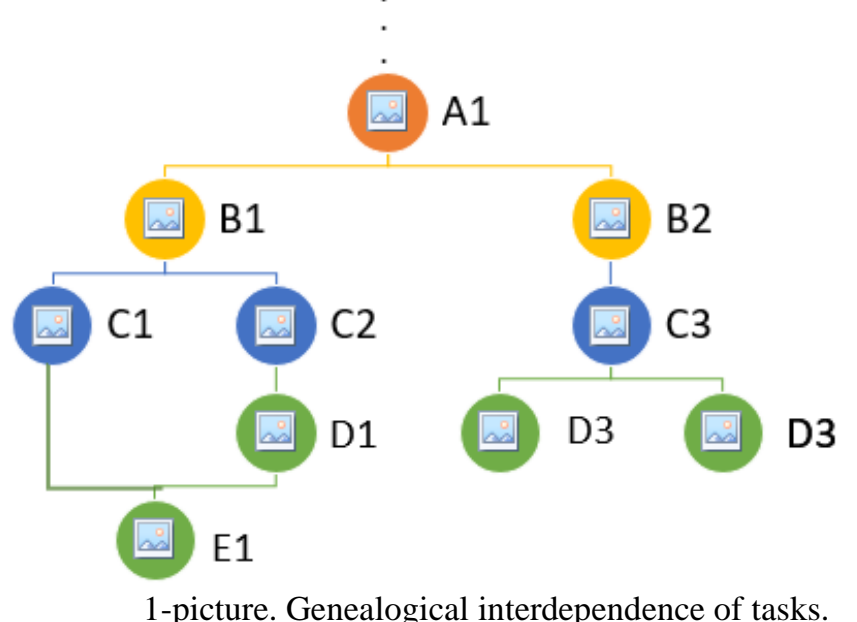

Genealogical tasks usually require the solution of one or more tasks for one task. The determination of the torture and ideas of solving such tasks constitutes a wide coverage of knowledge.

in the first picture, E1 is intended to complete the task, D1 and $\mathrm{C} 1$ are intended to complete the task, $\mathrm{D} 1$ is intended to complete the task, $\mathrm{C} 2$ is intended to complete the task, $\mathrm{C} 1$ and $\mathrm{C} 2$ are intended to complete the task, B1 is intended to complete the task, B1 is intended to complete the task, B1 is

As an example of genealogical tasks, make an algorithm for performing $\mathrm{A}^{4}$ through two actions. After this assignment, it is possible to apply $A^{8}$ to 3 units, apply $A^{16}$ to 4 units and complete assignments with $A^{2^{n}}$ to $N$ units.

Examples of genealogical assignments can also be obtained by following assignments:

First assignment. Given the Month Number (1-January, 2-February,...). Create an algorithm that finds the seasons of the year, respectively. ("winter", " spring "and etc).

Second assignment. Three integers are given. If the number is negative, then draw an algorithm that outputs the result by raising it to the square, if positive, to the cube.

The third assignment. The point lying on the arrows OX and OY is given. Point coordinates consist of a real number. Make an algorithm that determines which coordinate the given point is located. 
Four of these assignments are one-weight, and the last five assignments are two-weight. Since among the tasks it is possible to draw up an algorithm in the simplest form - this is the first one.

If the assignments are performed on a sequential basis, it means that it is expedient to determine the formation of the intellektual potential of the learner and to perform these tasks in a sequential manner.

Genealogical assignments also serve the students to find out the legalities. For example, let the following assignments are given:

a real number get given. Build algorithms using only the multiplication operation.

$a^{7}$ with four operations;

$\mathrm{a}^{3}$ and $\mathrm{a}^{10}$ with four Operation;

$\mathrm{a}^{4}$ and $\mathrm{a}^{20} \mathrm{a}^{2}$, with five practices;

$\mathrm{a}^{5}$ and $\mathrm{a}^{17}$ with six Operation;

$\mathrm{a}^{4}, \mathrm{a}^{12}$ and $\mathrm{a}^{28}$ with six follow-up.

These given assignments are one-and two-weight, and by simple modification it is possible to compile all the consecutive algorithms. The ability to find the same simple change serves to formulate and determine the intellektual potential of the learner.

Further assignments for genealogical tasks:

1. Make an algorithm that will find the sum of the numbers of the given number.

2. make an algorithm that finds the sum of the positive numbers between the numbers a and $b$.

3. make an algorithm that will find a list of common dividers between the numbers a and $b$.

4. Make an algorithm that will find the number of Taq numbers in a given column.

5. Make an algorithm that will find the number of N Fibonacci numbers. (the Fibonacci number is equal to the sum of the two numbers that came before it, and the first two are equal together. For example: 1 , $1,2,3,5, \ldots)$.

6. Make an algorithm that will find a list of Root numbers between the given two numbers. (The root number is a number that can only be divided by itself and together. For example: 5, 13, 11, 3).Берилган натурал сонни энг кичик жуфт рақамини топадиган алгоритм тузинг.

These assignments are used to determine exactly what 9-graders think, their skills in working with numbers and their numbers. It is based on the study of the structure of such assignments and their impact onualual capacity, intellektual capacity can be assigned to the formation-oriented tasks. But on the one hand, it seems that it is not even right to distinguish them. Because the identification of potential is also associated with the formation of invisible law.

When compiling algorithms, it is mainly combined with arithmetic operations, which include attitude and logical attitude (complex attitude) actions. These are the main elementary actions for drawing up amalar weights and genealogical assignments. Similarly, these actions are also elements in which there is a great deal of influence on the outcome of the algorithm to find and slightly change the rules of precision. In the Scratch program, these actions are listed in the" Actions " panel as elements as follows (2.1- table).

Relationship practices.

2.3- table.

\begin{tabular}{|c|c|c|c|}
\hline Operators & $\begin{array}{l}\text { Expression in } \\
\text { mathematics }\end{array}$ & Meaning & Example \\
\hline$<1$ & $<$ & Small & $\mathrm{a}<\mathrm{b}$ \\
\hline$=$ & $=$ & Equal & $a==b$ \\
\hline$>$ & $>$ & Large & $a>b$ \\
\hline and & $\& \&, \vee,($ and $)$ & Multiplication of two relationships & $(a>b) \& \&(c<d)$ \\
\hline or & $\|, \wedge$, (or) & The sum of the two relationships & $(a>b) \|(c<d)$ \\
\hline at & $!$, (not) & Reverse attitude & $!(a>b)$ \\
\hline
\end{tabular}

The organization and management of recurrence processes is also an important element when compiling algorithms. Too many algorithms, which are formed by students or encountered in life, have a repetitive process. In order to organize the process of repetition in the algorithm, the condition practice and the whole step-by-step repetition block scheme are used. But for the compilation of algorithms of Scratch repetition processes, elements of repetition are used that are oriented to programming exactly (2.4- look at the table) 
2.4- table.

Elements of drawing up the algorithms of the recurrence process.

\begin{tabular}{|l|l|}
\hline \multicolumn{1}{|c|}{ Elements } & \multicolumn{1}{c|}{ Meaning } \\
\hline
\end{tabular}

In order for the repetitions to always come out alive, the above mentioned Scratch program's repetition equipment is used. It is also possible to quit or continue the process of repetition, after obtaining a certain condition or value from the processes of repetition. Cutting or continuation operators are available in programming languages, but there are no drawing forms based on the block scheme. This repetitive equipment is used to shape the practical skills of drawing up Real algorithms and preparing students for its programming.

The process of networking is also a key factor in the creation of algorithms. Usually in the algorithm, which is compiled using a block scheme, the process of networking is carried out in full with a condition and several schemes of valid execution. In real-life algorithms, however, there are processes of networking that are complete and incomplete. Therefore, there are two elements in the Scratch program (2.5- look at the table)

\section{5- table.}

Equipment for the process of networking

\begin{tabular}{|l|l|}
\hline Elements & \multicolumn{1}{|c|}{ Meaning } \\
\hline & Networking complete the incomplete process \\
\hline & Complete the process in which the networking process is complete \\
\hline
\end{tabular}

One of the main features in the compilation of algorithms is a hint from the introduction of this new type of variable. Variable is used to store and refer to data during these algorithms (the same as the definition in mathematics). Such an option is located in the "information" panel of the Scratch program and is included in it an element for creating a special variable. To do this it is possible to create an optional variable in the Reader using the following steps must be completed.

1. It is entered in the" information " panel.

2. The" create variable " button is pressed and a dialog box appears on the screen (2.6- picture).

\section{New Variable}

\section{Variable name:}

For all sprites

OK
For this sprite only

\section{Cancel}

2.6- picture. Add new variable

1. The variable is given a name.

2. The type of variable is selected. If it is selected for all scripts, it is used for all algorithms in the current project, only if it is selected for the same skript, it is used for the current algorithms in the current project.

Scratch for the created variable is given by creating 5 pieces of hardware in the program (2.6 - table).

\section{6- table.}

Variable handling equipment.

\begin{tabular}{|c|l|c|}
\hline $\begin{array}{c}\text { Elements } \\
\text { (Ускуналар) }\end{array}$ & \multicolumn{1}{|c|}{ Function } & Meaning \\
\hline$\checkmark a$ & $\begin{array}{l}\text { Allows the use of the value of a variable. The selector, } \\
\text { however, determines whether to display its value to the } \\
\text { screen or vice versa. }\end{array}$ & \\
\hline
\end{tabular}




\begin{tabular}{|c|c|c|}
\hline & & (a) $+b$ \\
\hline set $\sqrt{a>}$ to 0 & Give a new value to a variable & set $\sqrt{a}$ to javob \\
\hline change $\sqrt{a \top}$ by 1 & Adding a number to a variable, give a new value & change $\sqrt{a v}$ by $b$ \\
\hline show variable $\longdiv { a ^ { 2 } }$ & Show fixing the value of a variable & show variable $\longdiv { a v }$ \\
\hline hide variable $\overline{a^{\top}}$ & Making a variable temporarily invisible & hide variable $\longdiv { a ^ { V } }$ \\
\hline
\end{tabular}

The process by which students come up with a lot of problematic situations when compiling algorithms is to work with the elements of this list (collection, mass). This requires the creation of additional algorithms for algorithms. And in the Scratch program, it is possible to create a special list for this and create equipment for its use.

To create a new list variable, the following steps are performed.

1. $\quad$ The" information " panel is entered.

2. The" Create New List " button is pressed and a dialog box appears on the screen (2.7picture.).

3. The list variable is named.

4. The type of list variable is selected. If it is selected for all scripts, it is used for all algorithms in the current project, only if it is selected for the same skript, it is used for the current algorithms in the current project.

\section{New Variable}

\section{Variable name:}

For all sprites

OK

\section{For this sprite only}

\section{Cancel}

2.7- picture. Add a new list variable

The new list created in Scratch for the variable is provided by creating 10 pieces of equipment designed to work with the list in the program (2.7- table).

\section{7- table.}

List variable handling equipment.

\begin{tabular}{|c|c|}
\hline Elements & Function \\
\hline$\checkmark A$ & $\begin{array}{l}\text { Allows the use of the values of a set variable. The selector, however, } \\
\text { determines whether to display its value to the screen or vice versa. }\end{array}$ \\
\hline add thing to $A=$ & Performs addition of a new element to a collection variable \\
\hline delete $1 \nabla$ of $\bar{A}$ V & $\begin{array}{l}\text { A collection variable allows you to delete the first, last, optional } \\
\text { element and all elements at once. }\end{array}$ \\
\hline insert thing at $1^{\mathrm{V}}$ of $\overline{\mathrm{A}^{\mathrm{V}}}$ & $\begin{array}{l}\text { It allows you to place the given value in the first, last, optional index } \\
\text { of a set variable. }\end{array}$ \\
\hline replace item $1>$ of $A>$ with & $\begin{array}{l}\text { It allows you to replace the given value with the value in the first, } \\
\text { last, optional index of the variable of a set. }\end{array}$ \\
\hline item $1 \nabla$ of $\overline{A \nabla}$ & $\begin{array}{l}\text { Returns the value of a collection variable in the first, last, optional } \\
\text { index. }\end{array}$ \\
\hline$A \nabla$ ning uzunligi & Returns the number of elements in a collection variable. \\
\hline
\end{tabular}




\begin{tabular}{|l|l|}
\hline$A>$ contains thing ? & $\begin{array}{l}\text { Is the given value contained in a set variable A? If there is } 1 \\
\text { otherwise } 0 \text { returns. }\end{array}$ \\
\hline show list $A \nabla$ & Displays the display of elements of a collection variable. \\
\hline hide list $A \nabla$ & Temporarily invisible elements of a collection variable \\
\hline
\end{tabular}

In order to stimulate the creativity of students in the Scratch program, the reader will also have the opportunity to create a new equipment for himself, aimed at fulfilling a certain goal of a special algorithm. To do this, you need to use the" more blocks " panel (2.8- look at the table).

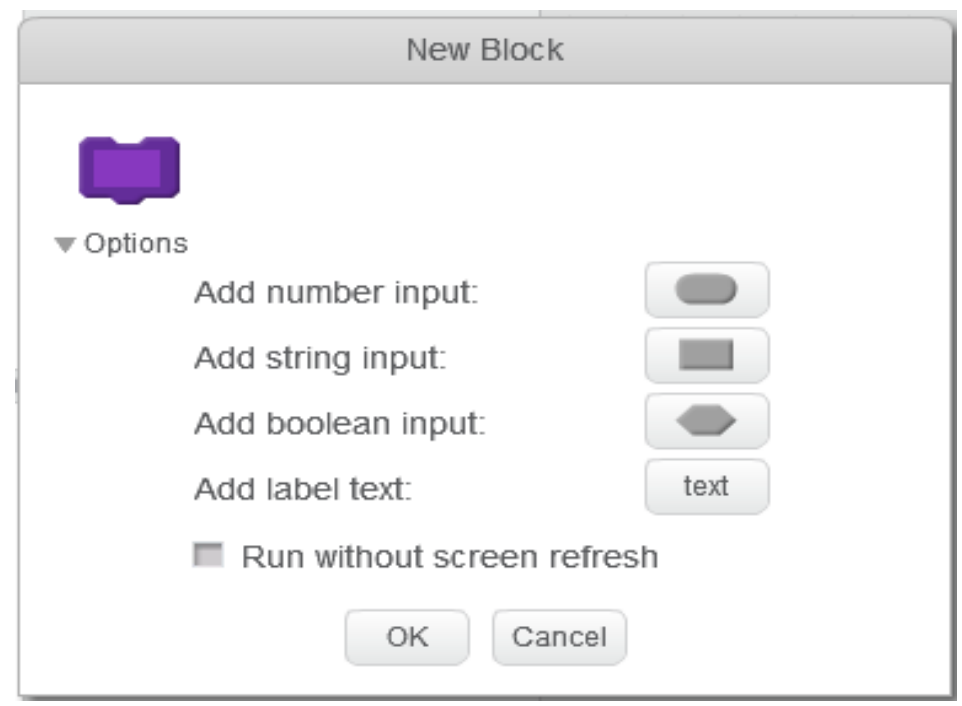

2.8- picture. New hardware creation window.

To create a new technique, it is enough to click the left mouse button on the desired area.

We cite the method of developing tasks for the formation of intellectual capacity based on the above algorithm-building equipment:

1. Weight task is developed (Issue 1).

2. The calculation expressions of the weighted task are changed $(2,3, \ldots, 10$-issue).

3. Weight is increased to one (issue 11).

4. The calculation expressions of the weighted task are changed $(12,13, \ldots, 20$-issue $)$.

Thus, the method of developing assignments for the formation of intellectual capacity can be adapted to the process of repetition, developing tasks up to 100 soles. Take, for example, to compile a one-weight task in the Scratch program and solve the next 9 task.

\section{Conclusion}

Thus, the algorithms of the remaining 8 issues are also compiled. The duration of this process will serve as the difference of the 2 task based on the functions of the variables, mathematical expressions, the equipment for the compilation of the used algorithms in the compilation of the student's task algorithms, then, the difference of the issues intellektual capacity formation.

We cite the method of developing assignments on the determination of intelectual capacity based on the equipment for constructing algorithms:

1. Weight task is drawn up (Issue 1). In this assignment there must be an aossi idea and a series of issues.

2. A task based on the main idea and a little thought-out is drawn up (Issue 2).

3. On the basis of developing the main idea, the next task is drawn up $(3,4, \ldots 10$-for example).

4. The main idea is radically changed, a new ideological task is created, and the category does not change(issue 11).

5. An idea-based and little thought-out task is drawn up (Issue 12).

6. On the basis of developing the idea, the next task is drawn up $(13,14, \ldots 20$-for example).

Thus, it is possible to develop tasks up to 100 soles, by adapting the method of developing assignments on the detection of intellectual potential to the process of repetition. Bunda will have different-looking algorithms for tasks, the weights of which are different and based on genealogy. The number of issues that the 
algorithm is structured by the students serves as the criterion for determining the potential intellektual. For example, it is possible to suggest the following issues:

1-assignment. Create an algorithm that determines the belonging of the given $\mathrm{C}$ number [a, b] to the cross-section.

2-assignment. Make an algorithm that determines the descent of the given $\mathrm{m}(\mathrm{x}, \mathrm{y})$ point into a rectangle with points $\mathrm{A}\left(\mathrm{x} \_1, \mathrm{y} \_1\right), \mathrm{B}\left(\mathrm{x} \_2, \mathrm{y} \_2\right)$ on the axis of the coordinates decart.

3 -assignment. On the axis of coordinates decart $\mathrm{a}(\mathrm{x} 1, \mathrm{y} 1)$ make an algorithm that determines the drop of the given $\mathrm{m}(\mathrm{x}, \mathrm{y})$ point into a given circle with a center and a radius.

The solutions for these tasks are compiled through the scratch program as follows.
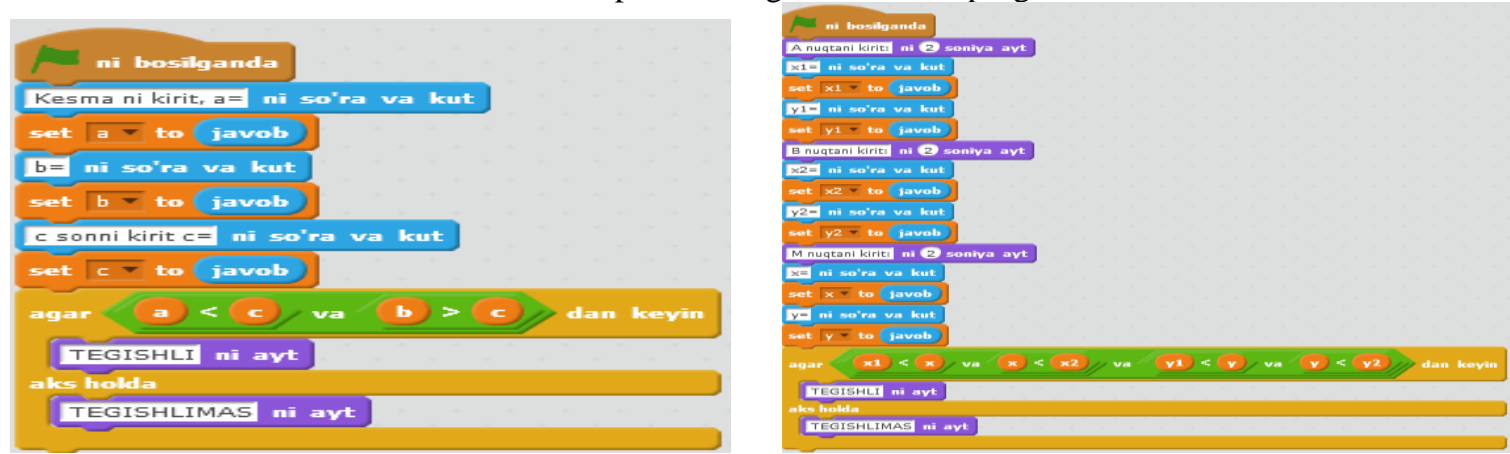

2.11- picture. 1- assignment algorithm. 2.12- picture.2- assignment algorithm

It is sufficient to use the idea of the previous assignment to take as an incision the 2 side of the rectangle, using the basic complex relationship to the algorithms.

One of the most important factors is the development of assignments for the formation and determination of intellektual capacity in the 9th grade students of secondary schools, their separation into weights, based on the laws of interdependence. It also requires research as a scientific and methodological issue to develop and implement the yakkaual capacity shaping single and subgroup approach and use methodology, intellektual capacity determination single and subgroup approach and use methodology in the course process.

\section{References:}

1. Muradova F.R. Using multimedia and communication technologies as a means to implement active learning methods // EUROPEAN RESEARCH, London, United Kingdom. - 2020. P. 25-26.

2. Muradova F.R. Types and structures of educational and methodological materials with computer support // Electronic journal of actual problems of modern science, education and training, №1. Khorezm. - 2020. P. 106-109.

3. Muradova F.R. Educational laboratory as a modern form of educational activity organization // International scientific review, Boston, - 2020. P. 41-42.

4. Muradova F.R., Murodova Z.R. Use of information technologies in education // International Journal of Psychosocial Rehabilitation, UK. -2020.- P. 3110-3116.

5. Muradova F.R. The use of innovative methods in education // Problems and prospects of education development, Krasnodar. - 2019. P. 62-63.

6. Muradova F.R. Game technologies are one of the most effective ways to teach students in computer science classes // Bulletin of magistracy, Yoshkar-Ola. - 2019. -P. 60-62.

7. Muradova F.R. Virtual labs in distance learning / Psychology and education, VOL. 58 №1, 2020. P. 45474551.

8. Muradova F.R. Game Technology for Science Lessons // Eastern European Scientific Journal, Germany. 2017. - P. 107-109.

9. Muradova F.R. Virtual laboratories in teaching and education. ISJ Theoretical \& Applied science. Philadelphia, USA. 2020. P. 106-109.

10. Yodgorova M.O. Muradova F.R., Muradova Z.R., Ataullaev Sh.N., Kadirova Sh.M. Psychological aspects of computer virtual reality perception // Journal of critical reviews, Vol 7, Issue 18, - 2020. P. 840-844.

11. Muradova F.R. Using the capabilities of virtual laboratories in the educational process // ACADEMICIA: An International Multidisciplinary Research Journal, India. - 2020. P. 349-354.

12. Muradova F.R. Virtual laboratories as promising information technologies in the educational process // Electronic journal of modern science, education and training, №4. Khorezm. - 2020. P. 17-22.

13. Murodova Z.R. Psychological and pedagogical aspect of the emergence of intellectual models of autor's tests. // Electronic journal of modern science, education and training, №1. Khorezm. - 2020. P. 284-291 
14. Murodova Z.R .Methods of formation and identification of intellectual potential in the field of information technologies. // Electronic journal of modern science, education and training, №4. Khorezm. - 2020. P. 5662

15. Muradova FR, Usmonova NY, Murodova ZR Unconventional forms of science lessons using game technology// European Conference on Innovations in Technical and Natural Sciences, 69-74 